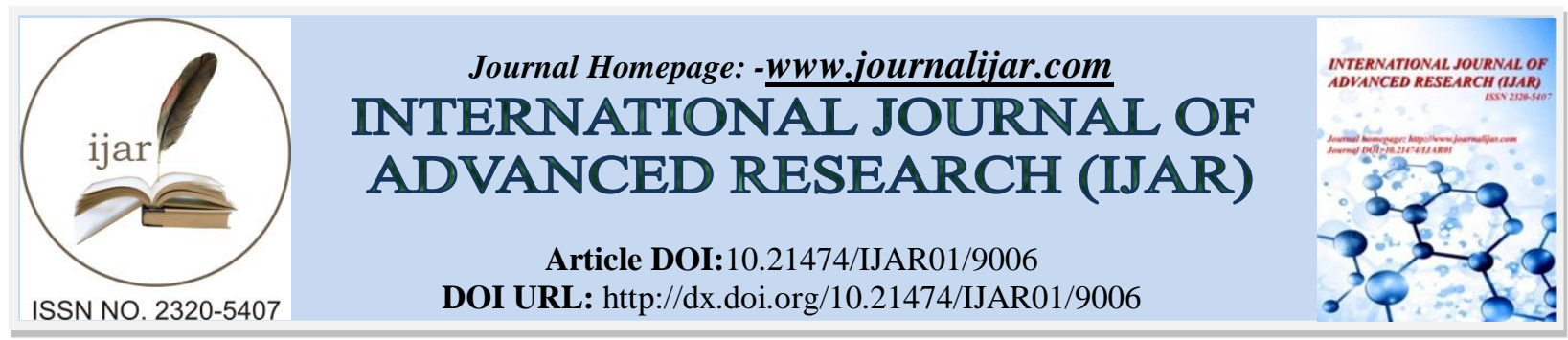

RESEARCH ARTICLE

\title{
BIFENTHRIN INDUCED BIOCHEMICAL AND HISTOPATHOLOGICAL ALTERATIONS IN RATS.
}

\section{Enas A. Tahoun ${ }^{1}$, Shimaa M. Abou-Zeid ${ }^{2}$ and Huda O. AbuBakr ${ }^{3}$.}

1. Department of Pathology, Faculty of Veterinary Medicine, University of Sadat City, Egypt.

2. Department of Forensic Medicine and Toxicology, Faculty of Veterinary Medicine, University of Sadat City.

3. Department of Biochemistry and Chemistry of Nutrition, Faculty of Veterinary Medicine, Cairo University, Giza, 12211, Egypt.

\section{Manuscript Info}

\section{Manuscript History}

Received: 02 March 2019

Final Accepted: 04 April 2019

Published: May 2019

Key words:-

Bifenthrin, oxidative stress, apoptosis, inflammation, histopathology.

\begin{abstract}
Bifenthrin is a third-generation synthetic pyrethroid with a broad spectrum insecticidal and acaricidal activity used to control a wide range of insect pests in many applications. The current study was designed to investigate the toxic effects of bifenthrin in male rats exposed orally by stomach intubation at $7 \mathrm{mg} / \mathrm{kg}$ for 28 days. Liver and kidney functions were monitored in addition to oxidant/antioxidant parameters in serum, liver, kidney and brain. The immunohistochemical reactivity to iNOS, COX-2 and caspase-3 were studied and the histopathological findings were recorded. Our results revealed significant elevations in serum ALT, AST, LDH and ALP activities and blood BUN and creatinine levels while serum total protein was reduced. The level of MDA increased in liver, kidney and brain with reduction in GSH level and SOD, CAT and GPx activities. The activity of iNOS increased in hepatocytes, glomeruli and renal tubular cells. Strong immunoreactivity to COX-2 was observed in the brain. The expression of caspase- 3 increased in both liver and brain. The liver revealed degeneration with loss of cellular outlines and areas of coagulative necrosis infiltrated with inflammatory cells. The kidney showed congestion of blood vessels and glomeruli, necrotic renal tubules and hyperplasia of fibrocytes with leucocyte infiltration inbetween renal tubules. The brain revealed loss of some Purkinje cells, demyelination, neuronophagia, widespread neuronal necrosis with marked edema and proliferation of perineural satellite oligodendroglia cells around the cell body of motor neurons 'satellitosis'. In conlusion, bifenthrin produced toxic effects in rats which seem to be mediated by oxidative stress and release of inflammatory mediators.
\end{abstract}

Copy Right, IJAR, 2019,. All rights reserved.

\section{Introduction:-}

Pyrethroids are a class of synthetic insecticides that have been designed and optimized based on the structures of the pyrethrins, the natural insecticides obtained from pyrethrum. Pyrethroids have been widely used in agricultural, urban and home environments over the last decades as a result of restrictions on the use of organophosphates and carbamates (Sunderland, 2010). Pyrethroids account for about 30\% of insecticides used globally because of their 
relative safety to human and animals, excellent insecticidal activity and rapid degradation in soil (Prasanthi et al., 2005).

Bifenthrin is a third-generation type I (non-cyano) pyrethroid insecticide and miticide widely used for agricultural and domestic pest control. Commercial bifenthrin products are used on vegetables, some fruits, corn, cotton, cereals, grass seed, alfa alfa, and ornamentals (Johnson et al., 2010). The use of bifenthrin is also preferred in veterinary practices and public health programs to control ectoparasites and disease vectors, respectively (Anadón et al., 2009).

The main target for pyrethroids in nerve cells is the voltage-gated sodium channel. Pyrethroids prolong the sodium tail current by retarding the closure of sodium channel gates after initial sodium influx during the depolarization phase. Because bifenthrin lacks the alpha cyano group, it binds with sodium channels transiently causing repetitive firing of axons without any effect on resting potential (Khan et al., 2013).

Due to its widespread use, residues of bifenthrin are frequently detected in environmental media, residential areas and biota, thus arising potential risks to the health of human and animals. Bifenthrin exhibited high acute lethal toxicity to aquatic species. Additionally, bifenthrin caused sublethal toxic effects on various non-target organisms, including developmental toxicity, neurobehavioral toxicity, immunotoxicity and endocrine disrupting effects (Yang et al., 2018).

However, the underlying mechanisms mediating bifenthrin toxicity are poorly understood so far. Generation of free radicals by other prethyroids through oxidation reactions mediated by cytochrome isoenzymes and through ester cleavage and subsequent oxidative stress have been previously demonstrated (Wang et al., 2016; Aouey et al., 2017).

Therefore, the current investigation was performed to evaluate the subacute toxicity of bifenthrin in relation to oxidative stress parameters, inflammatory mediators and apoptosis in rats orally exposed daily for 28 days. Haematoxylin and eosin staining was performed as a reference of examination of cytoarchitecture of tissues.

\section{Materials and Methods:-}

Chemicals

Bifenthrin $100 \mathrm{~g} / \mathrm{L}$ EC was purchased from King Quenson, China. Test kits for measuring liver and kidney functions and the oxidant/antioxidant biomarkers were obtained from Biodiagnostic (Egypt).

\section{Animals and experimental design}

The experimental design was approved by the Ethical Committee of Animal Experiments of University of Sadat City, Egypt, VUSC-002-1-19.

Young adult male Sprague-Dawley rats (150 - 200g) were purchased from Al-Zyade Experimental Animals Production Center (Giza, Egypt). Animals were maintained under standard experimental conditions (a 12-h light/dark cycle; temperature maintained $23 \pm 2{ }^{\circ} \mathrm{C}$ ) and supplied with food and water ad libitum.

Animals were randomly allocated into two groups, 25 animals each. The treated group received bifenthrin orally dissolved in corn oil for 28 days by stomach tube at a daily dose of $7 \mathrm{mg} / \mathrm{kg}$ body weight, equivalent to $1 / 10^{\text {th }} \mathrm{LD}_{50}$ (Tsuji et al., 2012). The other group received no chemical treatment and administered the vehicle only to serve as control.

\section{Samples collection}

Every week, 5 animals from each group were sacrificed under diethyl ether anesthesia and liver, kidney and brain were excised and fixed in $10 \%$ neutral buffered formalin for histopathological and immunohistochemical investigations.

At the end of experiment, blood samples were collected from both groups before sacrifice, under diethyl ether anesthesia, from the retro-orbital fossa using capillary tubes in aliquots containing heparin at $10 \mathrm{IU} / \mathrm{ml}$ of blood. Serum was collected and stored at $-20^{\circ} \mathrm{C}$ until used for biochemical analysis. Animals were sacrificed and liver, kidney and brain were excised immediately and stored at $-80^{\circ} \mathrm{C}$ for further tissue biochemical analysis. 


\section{Liver and kidney function tests}

The influence of bifenthrin on liver function was evaluated by measuring the activities of serum alanine aminotransferase (ALT), aspartate aminotransferase (AST) (Reitman and Frankel, 1957), alkaline phosphatase (ALP) (EL-Aaser et al., 1977), lactate dehydrogenase (LDH) (Bais and Philcox, 1994) and levels of total protein (Gornall et al., 1949). Kidney function was assessed by measuring serum levels of BUN (Fawcett and Scott, 1960) and creatinine (Schirmeister et al., 1964).

\section{Oxidant/antioxidant biomarkers}

Total antioxidant capacity (TAC) in serum was estimated according to Koracevic et al. (2001). The level of malondialdehyde (MDA) (Ohkawa et al. 1979) was estimated in liver, kidney and brain. Glutathione reduced (GSH) level (Beutler et al., 1963) was measured in addition to activities of superoxide dismutase (SOD) (Nishikimi et al., 1972), catalase (CAT) (Aebi, 1984) and glutathione peroxidase (GPx) (Paglia and Valentine, 1967) in liver, kidney and brain.

\section{Immunohistochemistry}

For immunohistochemical staining, $4 \mu \mathrm{m}$ thick sections were fixed at $65^{\circ} \mathrm{C}$ for $1 \mathrm{~h}$, deparaffinized, rehydrated, and endogenous peroxidase activity was blocked with $3 \% \mathrm{H}_{2} \mathrm{O}_{2}$ in methanol. Sections were pre-treated in citrate buffer ( $\mathrm{pH}$ 6.0) in a microwave then incubated overnight at room temperature with rabbit polyclonal antibodies against inducible nitric oxide synthase (iNOS), cyclooxygenase-2 (COX-2) and caspase-3 according to their manufacturer's specification. The sections were incubated with biotinylated goat anti-polyvalent, then with streptavidin peroxidase and finally with diaminobenzedine plus chromogen. Slides were counterstained with hematoxylin before examination under the light microscope. The slides were visualized under light microscope and the extent of cell immunopositivity was assessed. Photos were photographed using a digital Leica photomicroscope (LEICA DMLB Germany).

\section{Semiquantitative scoring}

\section{Immunohistochemical evaluation of the tissues}

Semiquantitative data analysis of each parameter was performed in five rats from each group and three randomly selected different microscopic fields from each rat. The total number of cells in the microscopic field was calculated by counting hematoxylin-positive cells and immunopositive cells after performing color deconvolution command. Results were the mean value of counting fifteen sections. The mean prevalence of each parameter was performed according to the number of immunopositively stained cells compared to total number of cells with scores ranging from (-) to (+++) and degree of staining of immune positively stained cells with scores ranging from (0) to (III).

\begin{tabular}{|l|l|}
\hline \multicolumn{1}{|c|}{ Number of immune stained cells } & \multicolumn{1}{c|}{ Degree of staining } \\
\hline$(-):(0 \%$ no immune-positive cells $)$ & $(0):$ negative staining \\
\hline$(+):(<25 \%$ immune-positive cells $)$ & $($ I): weak staining \\
\hline$(++):(25-50 \%$ immune-positive cells $)$ & (II): moderate staining \\
\hline$(+++):(>50 \%$ immune-positive cells $)$ & (III): strong staining \\
\hline
\end{tabular}

\section{Histopathological examination}

Following necropsy, tissue specimens from liver, kidneys and brain were collected and rapidly fixed in $10 \%$ neutral buffered formalin solution. The fixed specimens were trimmed, washed, dehydrated in ascending grades of ethyl alcohol, cleared in methyl benzoate and processed through the conventional paraffin embedding technique. Paraffin blocks were prepared from which 3-5 $\mu$ microns sections were obtained using microtome (LEICA RM 2135) then routinely stained by hematoxylin and eosin (H \& E) stain according to Bancroft and Gamble (2008). Stained slides were microscopically analyzed using light microscopy. Histopathological Photos were photographed using a digital Leica photomicroscope (LEICA DMLB Germany).

\section{Statistical analysis:}

Statistical analysis was determined by student $t$ test. All statistical analyses were performed using SPSS (Statistical package for Social Sciences) Version 17. Values were presented as mean \pm SE. Differences were considered statistically significant at $\mathrm{P} \leq 0.05$ and $\mathrm{P} \leq 0.01$. 


\section{Results:-}

Liver and kidney functions

Subacute administration of bifenthrin to rats caused significant elevations $(\mathrm{P} \leq 0.01)$ in serum activities of ALT, AST, LDH and ALP, while the level of total protein was reduced (Table 1). The levels of serum BUN and creatinine were significantly elevated $(\mathrm{P} \leq 0.01)$ in bifenthrin treated rats.

Table 1:-Serum biochemical parameters in control and bifenthrin-treated rats

\begin{tabular}{|l|c|c|}
\hline & Control & Treated \\
\hline ALT $(\mathrm{u} / \mathrm{l})$ & $38.6 \pm 1.220$ & $80.8 \pm 1.53^{* * *}$ \\
\hline AST $(\mathrm{u} / \mathrm{l})$ & $83.3 \pm 1.86$ & $103.2 \pm 2.09^{* * *}$ \\
\hline LDH $(\mathrm{u} / \mathrm{l})$ & $962.8 \pm 5.96$ & $1317.4 \pm 9.36^{* *}$ \\
\hline ALP & $182.8 \pm 2.42$ & $200.6 \pm 3.41^{* * *}$ \\
\hline Total protein $(\mathrm{g} / \mathrm{dl})$ & $5.98 \pm 0.140$ & $4.81 \pm 0.128^{* * *}$ \\
\hline BUN $(\mathrm{mg} / \mathrm{dl})$ & $50.2 \pm 1.36$ & $95.6 \pm 1.94^{* * *}$ \\
\hline Creatinine $(\mathrm{mg} / \mathrm{dl})$ & $1.18 \pm 0.019$ & $2.72 \pm 0.114^{* *}$ \\
\hline TAC $(\mathrm{mmol} / \mathrm{L})$ & $1.25 \pm 0.048$ & $0.56 \pm 0.031^{* * *}$ \\
\hline
\end{tabular}

Values are presented as mean $\pm \mathrm{SE}, \mathrm{n}=5$. **Significant at $\mathrm{P} \leq 0.01$

Oxidant/antioxidant biomarkers

Serum total antioxidant capacity $(\mathrm{TAC})$ was significantly reduced $(\mathrm{P} \leq 0.01)$ in treated rats compared to control values (Table 1). Fig. 1 revealed significant increase $(P \leq 0.01)$ in MDA and NO levels in liver, kidney and brain of treated animals while the concentration of glutathione reduced decreased significantly $(\mathrm{P} \leq 0.01)$ in these organs. The activities of antioxidant enzymes SOD, CAT and GPx in the three organs were significantly suppressed due to bifenthrin treatment (Fig 2).

a
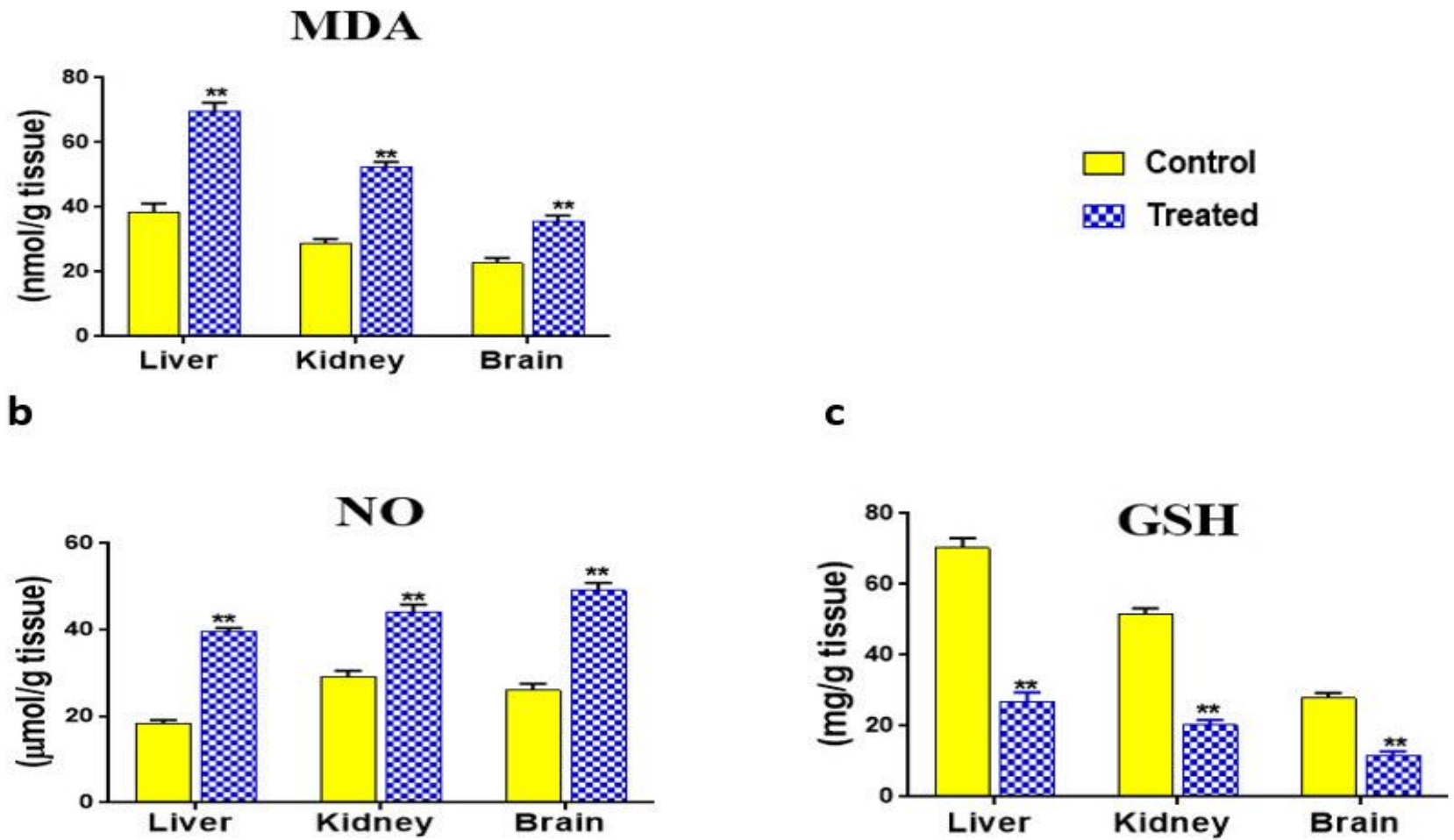

Fig 1:-Effect of bifenthrin on levels of a) malondialdehyde (MDA), b) Nitric oxide (NO) and c) glutathione (GSH) in liver, kidney and brain of control and treated rats. Values are presented as mean $\pm \mathrm{SE}, \mathrm{n}=5$, ${ }^{* *}$ significant at $\mathrm{P} \leq$ 0.01 . 
a

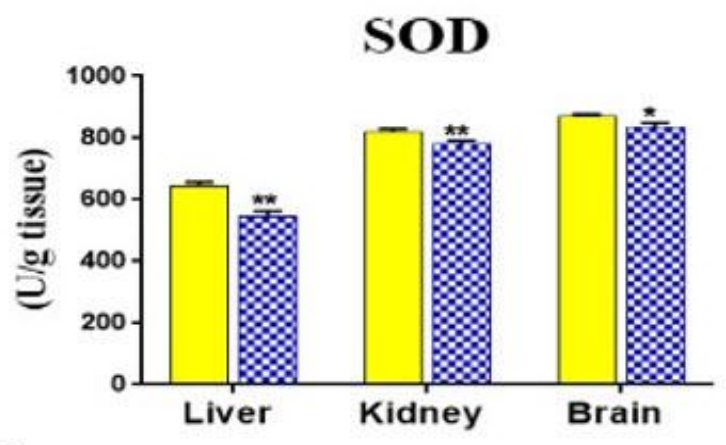

b
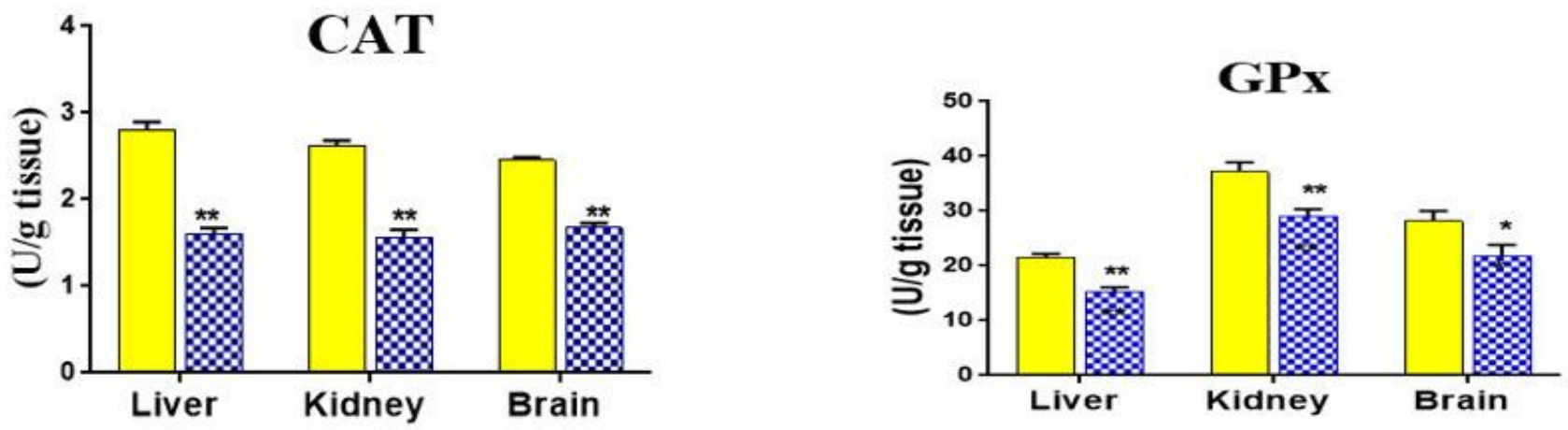

Fig 2:-Activities of a) superoxide dismutase (SOD), b) catalase (CAT) and c) glutathione peroxidase (GPx) in liver, kidney and brain of control and treated rats. Values are presented as mean $\pm \mathrm{SE}, \mathrm{n}=5$, * significant at $\mathrm{P} \leq 0.05$, ** significant at $\mathrm{P} \leq 0.01$.

\section{Immunohistochemical findings}

Our findings reveald that subacute administeration to bifenthrin incresed iNOS immunoractivity in hepatocytes in a time-dependent manner (Table 2, Fig. 3). In the kidney, strong immunoreactivity was observed in glomeruli, renal tubules and in-between medullary tubules in a manner proportional to the time of exposure (Table 2, Fig. 4).

Concerning COX-2, the immunoreactivity increased in intensity and distribution with increasing time of exposure, so that after 4 weeks strong immunoreactions were distributed all over the cerebrum (Table 2, Fig. 5).

Regarding caspase-3, significant increase in hepatocytes with intense caspase-3 immunoreactivity was observed (Table 2, Fig. 6). In brain, most of neurons revealed strong expression of caspase-3 (Table 2, Fig. 7). 

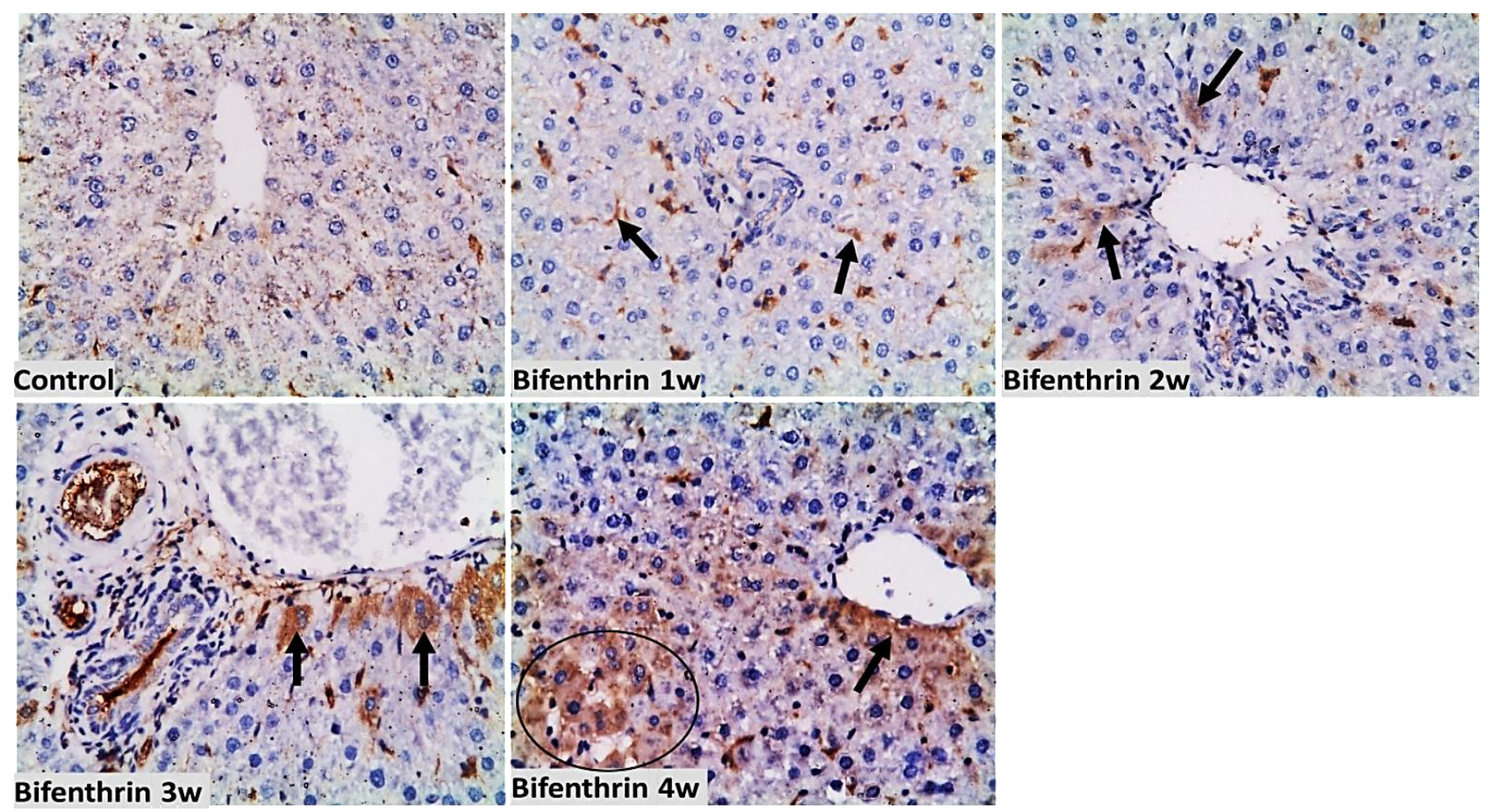

Fig 3:-Representative photomicrographs of iNOS expression in rat liver (X20).

Control group: showing no cytoplasmic iNOS immunoreactivity in the hepatocytes except for a line demarcation of sinusoidal endothelial cells by iNOS. Bifenthrin 1w: showing iNOS immunoreactivity in sinusoidal endothelial cells. Bifenthrin 2w: showing weak iNOS immunoreactivity in the cytoplasm of some hepatocytes (arrows) in the portal area. Bifenthrin 3w: showing strong iNOS immunoreactivity in the cytoplasm of multiple hepatocytes in the portal area (arrows). Bifenthrin 4w: showing increased number of iNOS-positive hepatocytes (the majority of these cells exhibited a strong intensity (circle).

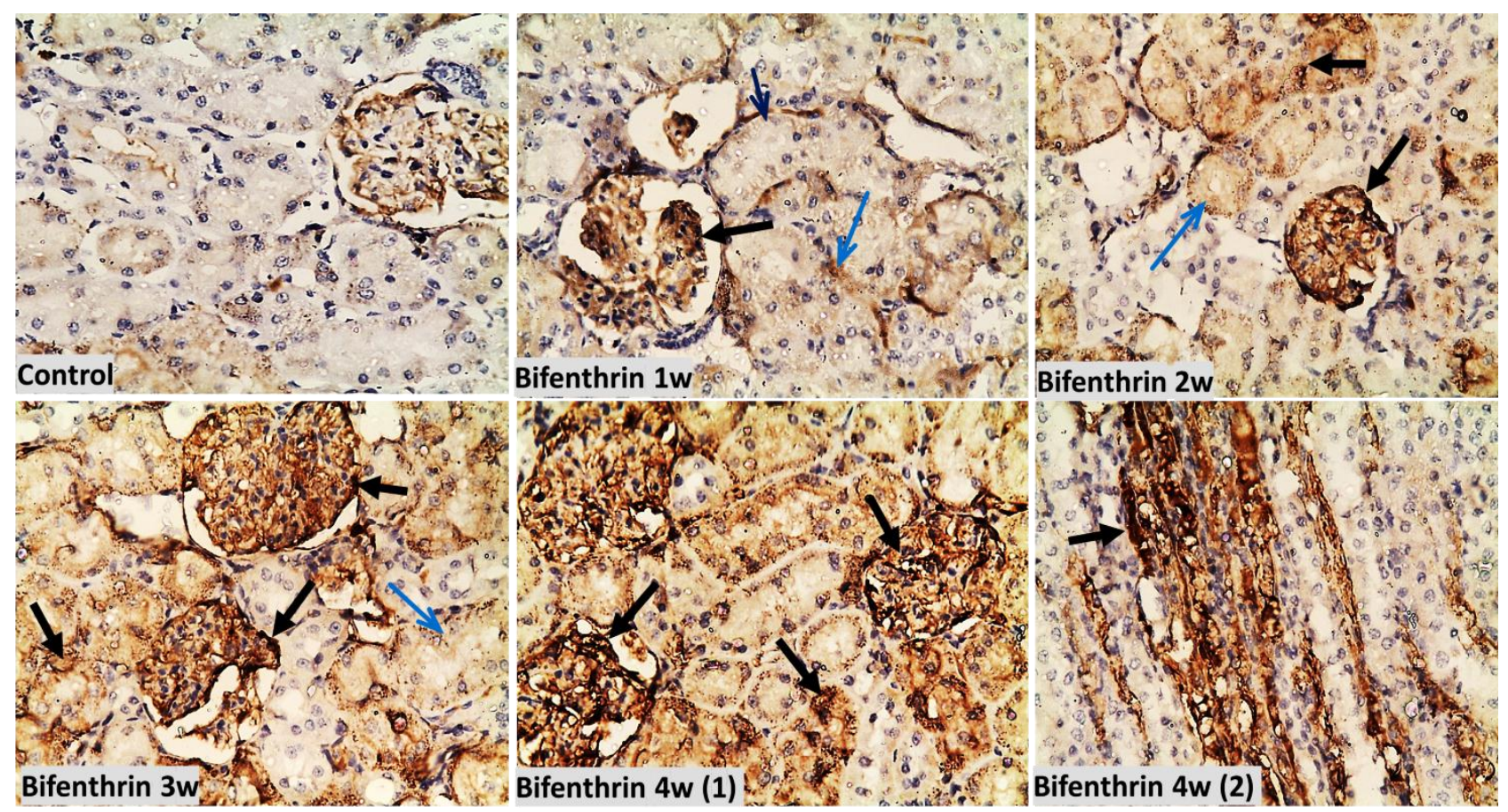

Fig 4:-Representative photomicrographs of iNOS expression in rat kidneys (X20), (black arrow: strong iNOS immunoreactivity; blue arrow: weak iNOS immunoreactivity). 
Control group: showing light immunoreactivity in the glomeruli and sporadic renal tubules. Bifenthrin 1w: showing strong iNOS immunoreactivity in the glomeruli and weak immunoreactivity in renal tubules. Bifenthrin 2w: showing strong immunoreactivity in the glomeruli and some renal tubules. Bifenthrin 3w: showing strong immunoreactivity in the glomeruli and most of renal tubules. Bifenthrin 4w: showing strong immunoreactivity in both glomeruli and renal tubules in cortical region of the kidney (1) and in-between medullary tubules (2).
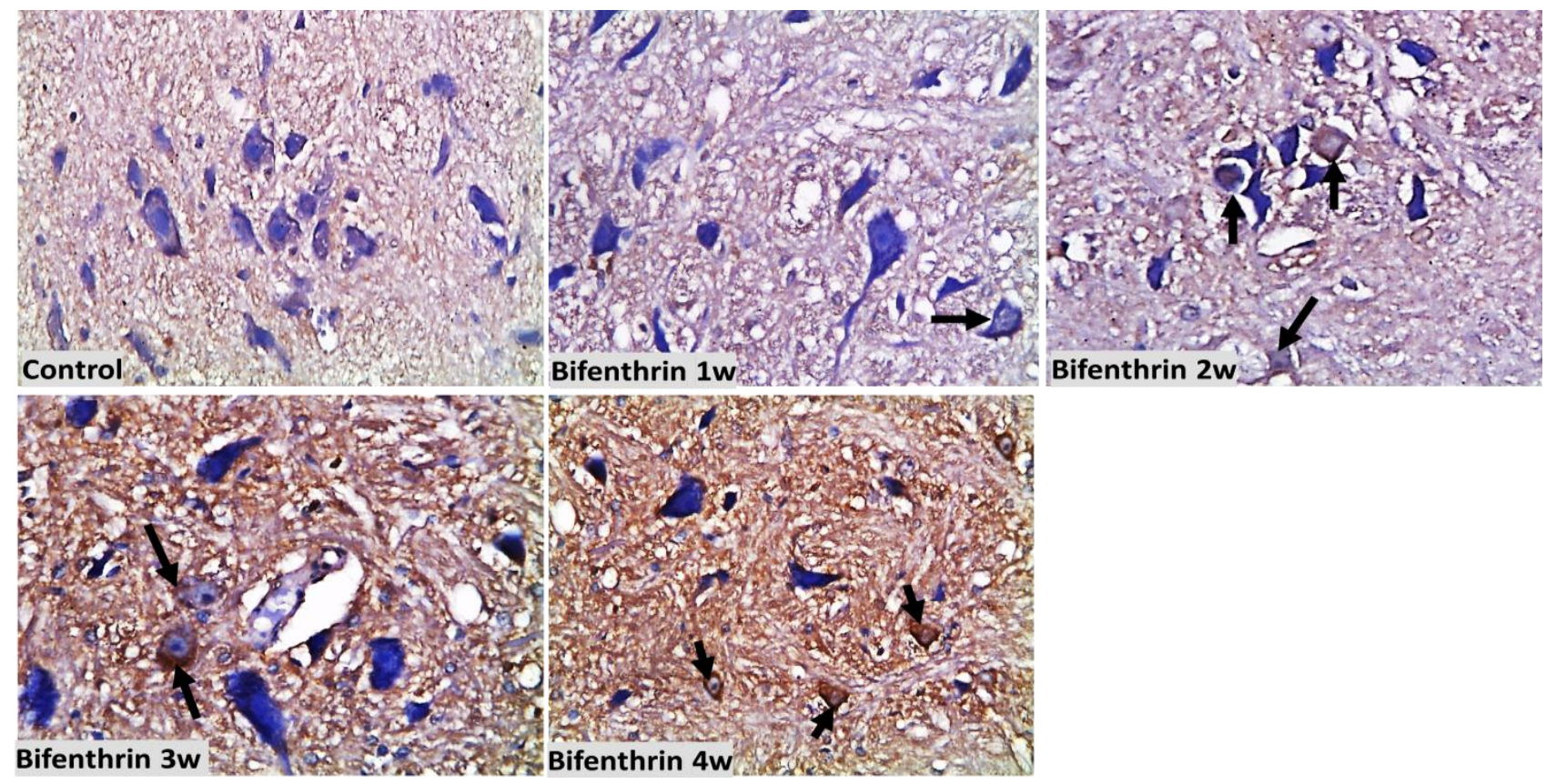

Fig 5:-Representative photomicrographs of COX-2 expression in rat cerebrum (motor neurons) (X20).

Control group: showing no COX-2 immune-stained cells. Bifenthrin 1w: showing sporadic scattered individual COX-2 immune-stained cell (arrow). Bifenthrin 2w: showing some immune-stained cell (arrow). Bifenthrin 3w: showing multiple immune-stained cells (arrows). Bifenthrin 4w: showing numerous COX-2 immune-stained cells with strong immune reaction distributed all over the cerebrum with perinuclear immunoreactivity.
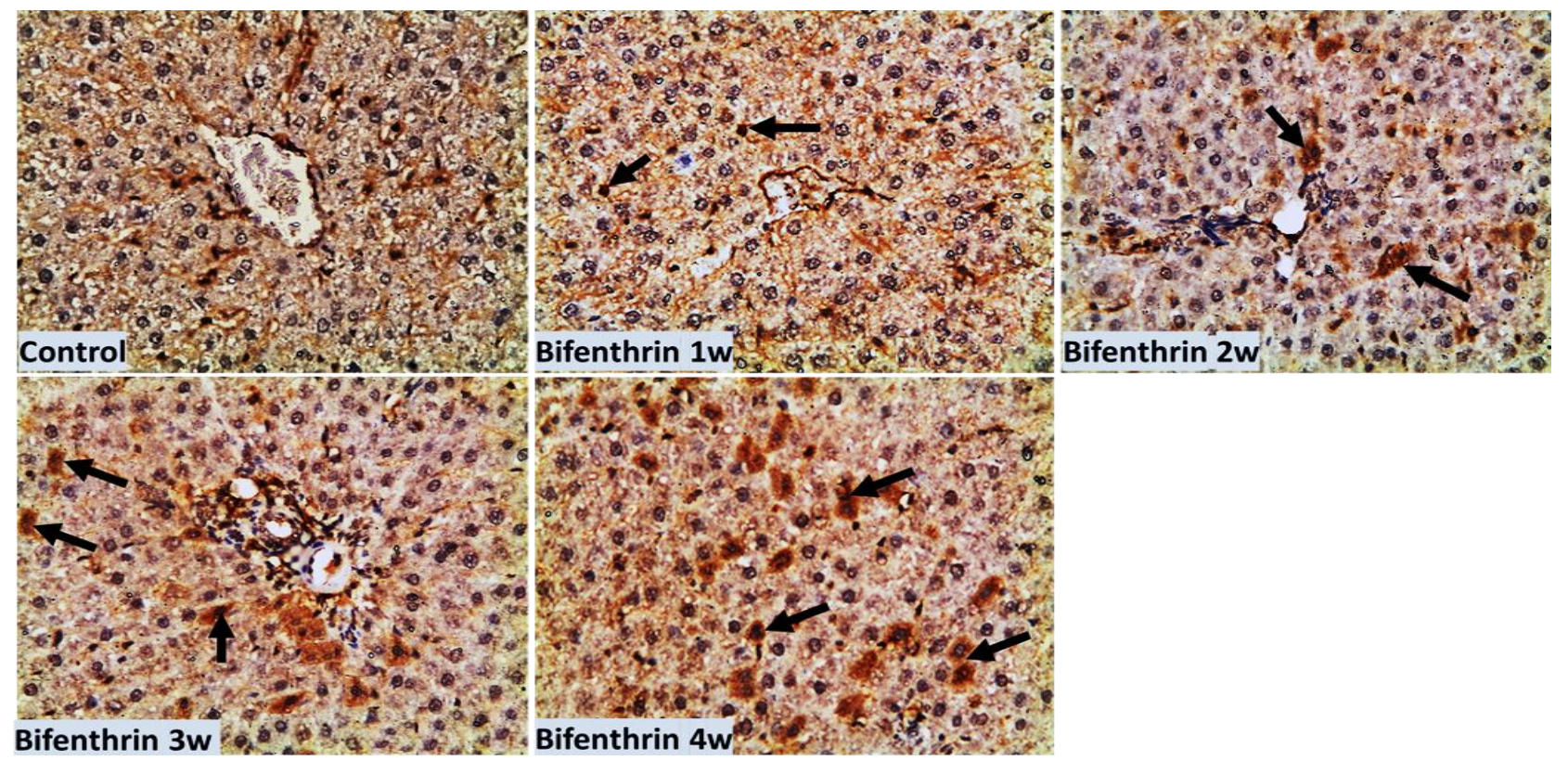

Fig 6:-Representative photomicrographs of immunohistochemistry for caspase-3 in rat liver (X20). 
Control group: showing hepatocytes with no expression of caspase-3. Bifenthrin 1w: showing sporadic scattered hepatocytes with caspase-3 immune reaction (arrows). Bifenthrin 2w: showing some hepatocytes with strong positive caspase-3 immune reaction (arrows). Bifenthrin 3w: showing multiple hepatocytes with intense immune reaction in the portal area (arrows). Bifenthrin 4w: showing a significant increase of hepatocytes with intense caspase-3 immunoreactivity (arrows).
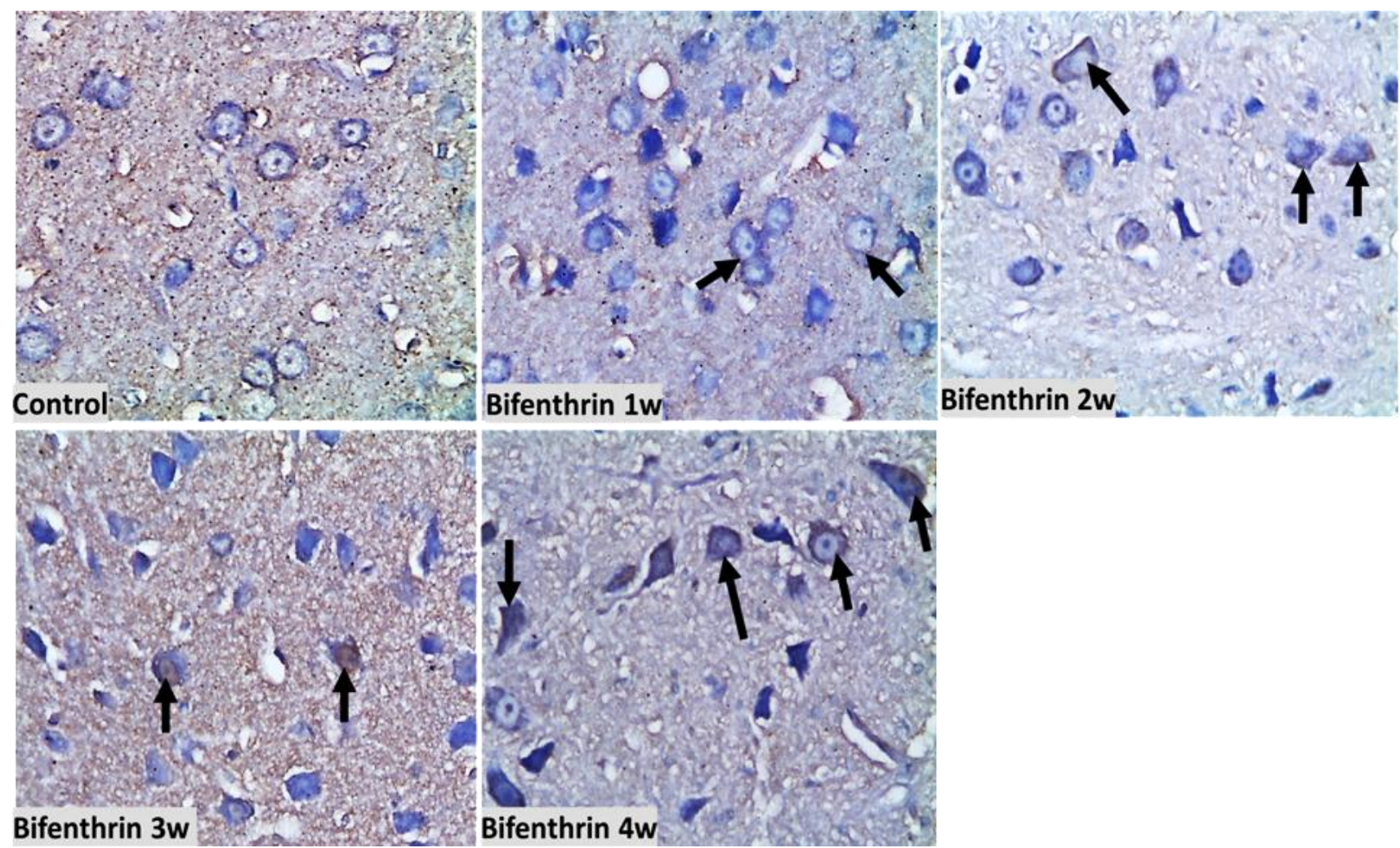

Fig 7:-Representative photomicrographs of immunohistochemistry for caspase-3 in rat mid brain (cerebral cortex) (X20).

Control group: showing normal neurons with no expression of caspase-3. Bifenthrin 1w: showing some neurons with weak expression of caspase-3. Bifenthrin 2w: showing neurons with weak expression of caspase-3. Bifenthrin 3w: showing neurons with strong expression of caspase-3. Bifenthrin 4w: showing most neurons with strong expression of caspase-3.

Table 2:-Distribution of histopathological grades of semiquantitative analysis of Immunohistochemical evaluation of liver, kidney and brain in rats.

\begin{tabular}{|c|c|c|c|c|c|c|c|c|c|}
\hline & \multicolumn{8}{|c|}{$\begin{array}{l}\text { Weeks of experiment } \\
\text { Histopathological grades }\end{array}$} \\
\hline \multirow[t]{2}{*}{ Parameter } & \multirow[t]{2}{*}{ Organ } & \multicolumn{2}{|c|}{$1 w$} & \multicolumn{2}{|r|}{$2 w$} & \multicolumn{2}{|c|}{$3 w$} & \multicolumn{2}{|c|}{$4 w$} \\
\hline & & Control & Bifenthrin & Control & Bifenthrin & Control & Bifenthrin & Control & Bifenthrin \\
\hline \multirow[t]{2}{*}{ iNOS } & Liver & $-(0)$ & $+(\mathrm{I})$ & $-(0)$ & $++(\mathrm{I})$ & $-(0)$ & ++ (II) & $-(0)$ & ++ (III) \\
\hline & kidney & $+(\mathrm{I})$ & $+(\mathrm{II})$ & $+(\mathrm{I})$ & ++ (III) & $+(\mathrm{I})$ & $+++($ III) & $+(\mathrm{I})$ & $+++(\mathrm{III})$ \\
\hline Cox-2 & Brain & $-(0)$ & $+(\mathrm{I})$ & - (0) & $+(\mathrm{I})$ & $-(0)$ & $++($ III) & - (0) & ++ (III) \\
\hline \multirow[t]{2}{*}{ Caspase-3 } & Liver & $-(0)$ & $+(\mathrm{II})$ & $-(0)$ & $+($ III) & $-(0)$ & ++ (III) & $-(0)$ & ++ (III) \\
\hline & Brain & $-(0)$ & $+(\mathrm{I})$ & $-(0)$ & $+(\mathrm{I})$ & $-(0)$ & ++ (III) & $-(0)$ & ++ (III) \\
\hline
\end{tabular}




\section{Histopathological findings}

Control animals showed normal histology of liver, kidney and brain (Fig. 8). After one week of bifenthrin treatment, liver showed congestion of central vein and sinusoids, granular degeneration of hepatocytes with granular cytoplasm. Edema in the portal area and coagulative necrosis of hepatocytes were recorded after 2 weeks. Congestion and edema in the portal area with inflammatory cell infiltration and coagulative necrosis of hepatocytes were noted after 3 weeks. At the end of experiment, the liver showed degenerated area with loss of cellular outlines (prescence of pyknotic nuclei and more esinophilic cytoplasm) and areas of coagulative necrosis infiltrated with inflammatory cells in the portal area.

Kidneys of treated animals showed congestion of glomeruli, edema of interstitial tissue, necrotic renal tubules and cloudy swelling of most renal tubules (Fig. 9). Hemorrhage, edema and inflammatory cell infiltration of interstitial tissue were noted after 2 weeks. At the third week, kidney revealed periglomerular hyperplasia of fibrocytes with leucocyte infiltration inbetween renal tubules and cloudy swelling of most renal tubules with hyaline and epithelial casts. At the end of experiment, the kidney revealed congestion of blood vesseles and glomeruli, necrotic renal tubules and hyperplasia of fibrocytes with leucocyte infiltration inbetween renal tubules.

The brain of control rats revealed normal histological architectures (Fig 10). After one week, brain of treated rats revealed necrosis of some Purkinje cells, mild congestion, neuronophagia, perineuronal edema and hemorrhage. After 2 weeks, necrosis of most of Purkinje cells, diffuse gliosis, proliferation of microglia cells around dead neurons (beginning of neuronophagia) and neuronal necrosis were observed. After 3 weeks, widespread necrosis of Purkinje cells, diffuse gliosis, necrotic neurons, neuronal necrosis and perineural edema were observed. At the end of experiment, brain revealed loss of some Purkinje cells, demyelination, neuronophagia, widespread neuronal necrosis with marked edema and proliferation of perineural satellite oligodendroglia cells around the cell body of motor neurons 'satellitosis'.

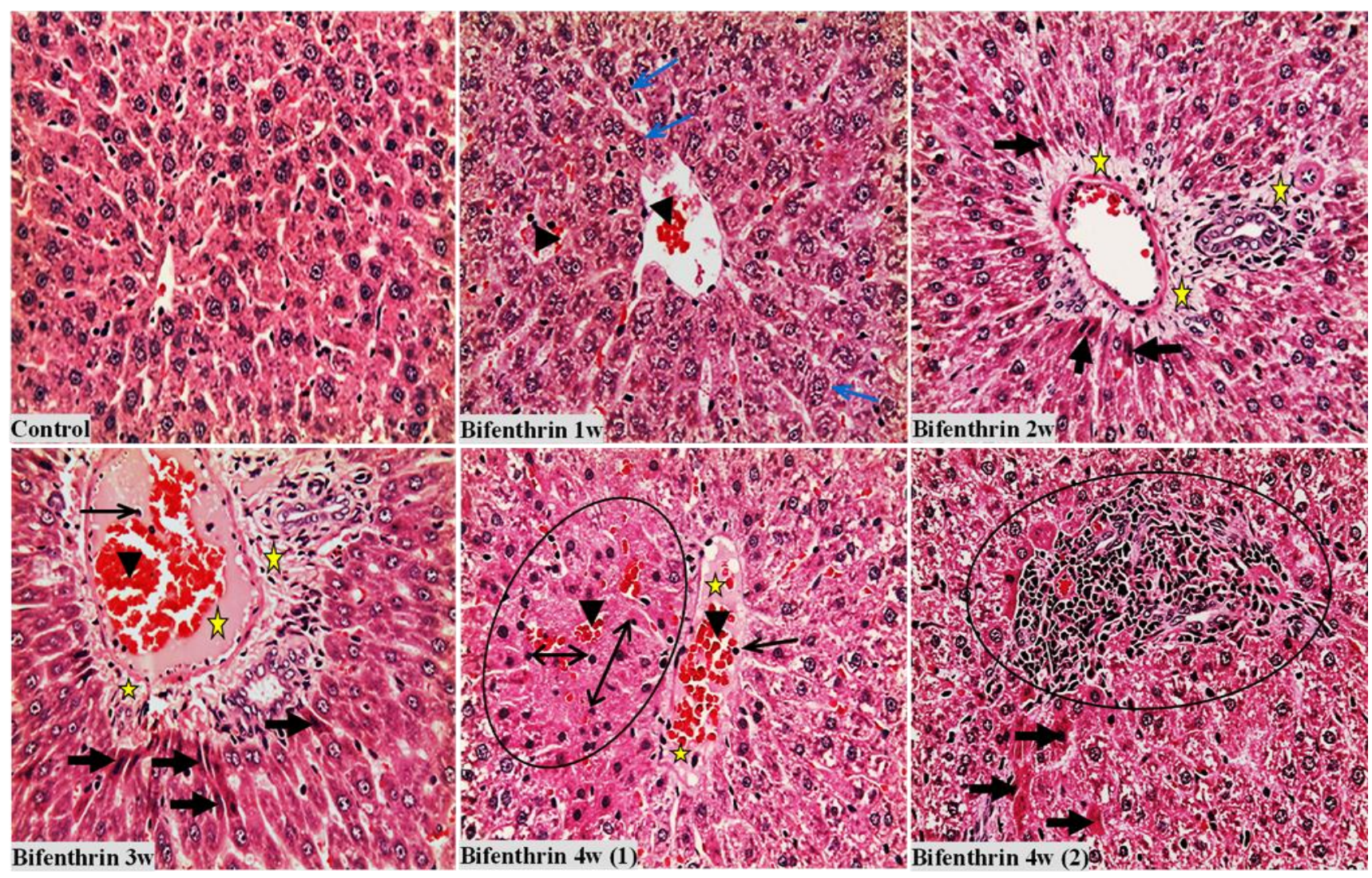

Fig 8:-Representative photomicrographs of liver sections of rats in different groups (H\&E X20). \{edema (star); congestion (head arrow); pyknotic nuclei (double head arrow); coagulative necrosis (thick black arrow); inflammatory cell infiltration (thin black arrow); granular degeneration of hepatocytes (blue arrow) \} 
Control group: showing normal histology. Bifenthrin group 1w: showing congestion of central vein and sinusoids, granular degeneration of hepatocytes. Bifenthrin 2w: showing edema in the portal area, coagulative necrosis of hepatocytes. Bifenthrin $3 \mathrm{w}$ : showing congestion and edema in the portal area with inflammatory cell infiltration and coagulative necrosis of hepatocytes. Bifenthrin 4w: (1) showing degenerated area with loss of cellular outlines (prescence of pyknotic nuclei and more esinophilic cytoplasm). (2) showing area of coagulative necrosis infiltrated with inflammatory cells in the portal area.

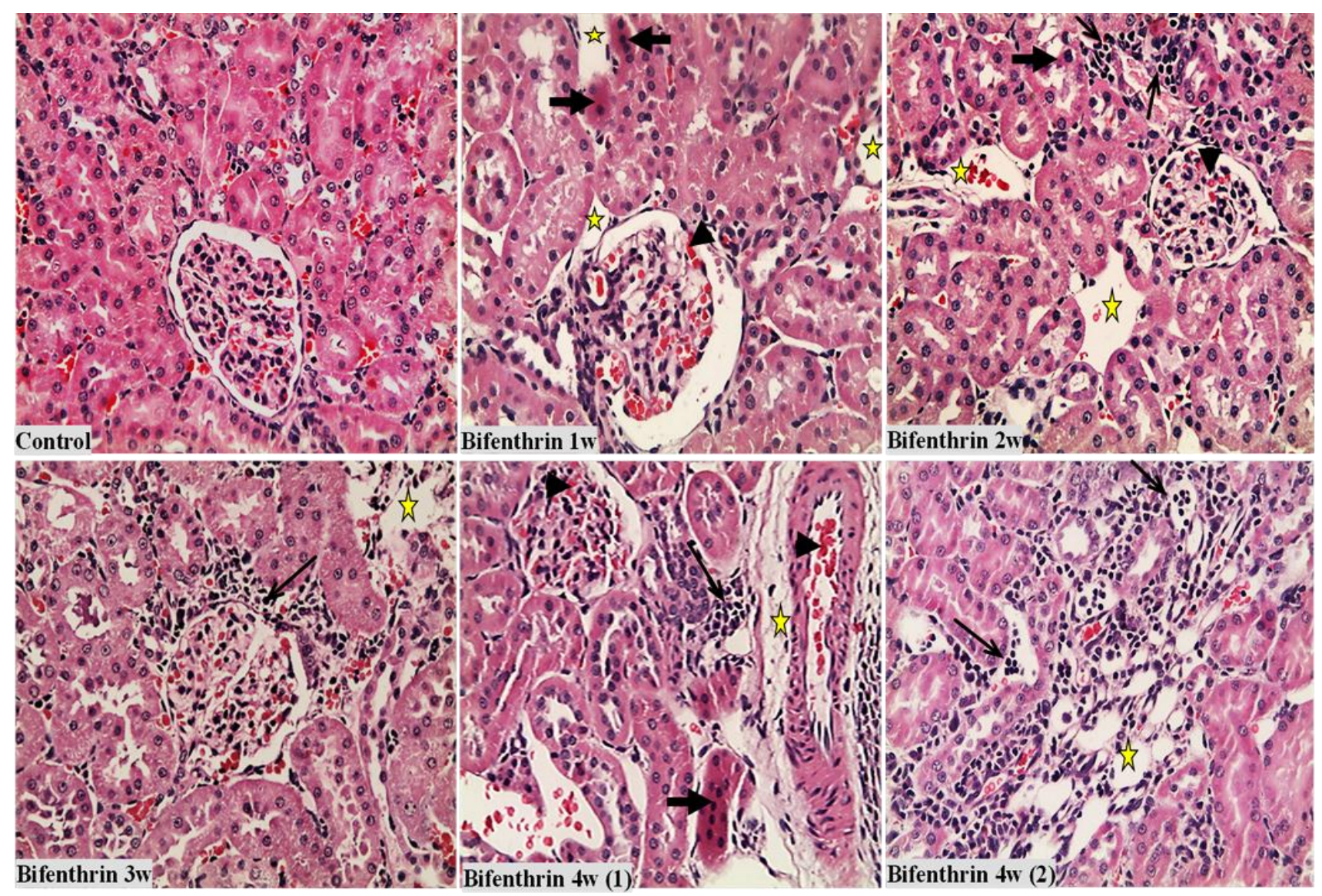

Fig 9:-Representative photomicrographs of Kidney sections of rats in different groups (H\&E X20). \{Edema (star); necrosis (thick arrow); congestion (head arrow); inflammatory cell infiltration (thin arrow) \}

Control group: showing normal histology. Bifenthrin group 1w: showing congestion of glomeruli, edema of interstitial tissue, necrotic renal tubules and cloudy swelling of most renal tubules. Bifenthrin 2w: showing hemorrhage, edema and inflammatory cell infiltration of interstitial tissue. Bifenthrin 3w: showing periglomerular hyperplasia of fibrocytes with leucocyte infiltration also inbetween renal tubules, cloudy swelling of most renal tubules with hyaline and epithelial casts. Bifenthrin 4w: (1) showing congestion of blood vesseles and glomeruli, necrotic renal tubules, (2) showing hyperplasia of fibrocytes with leucocyte infiltration inbetween renal tubules. 


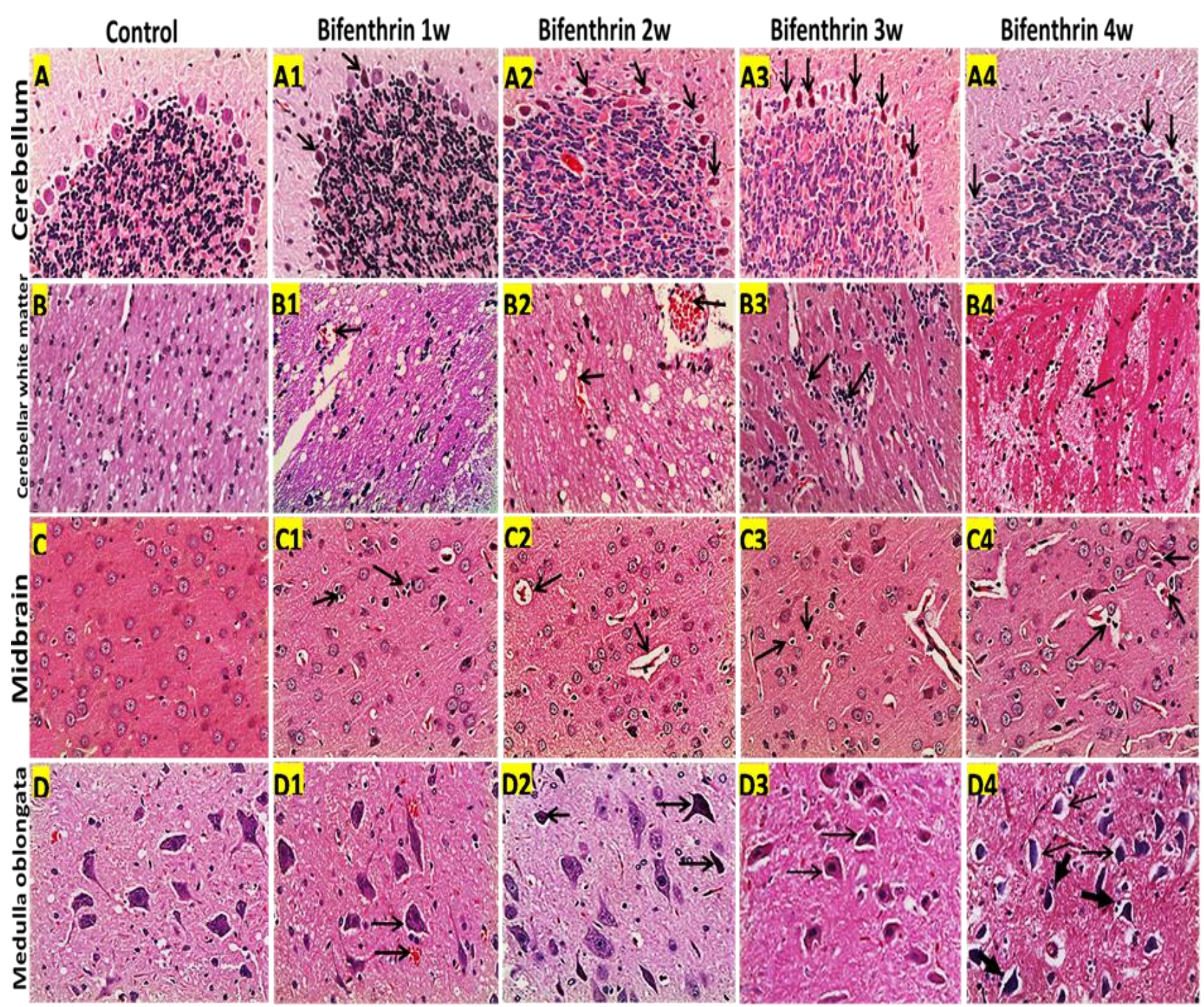

Fig 10:-Representative photomicrographs of brain sections of rats in different groups $\left(H \& E X_{20}\right)$. A, B, C \& D represent: cerebellum, cerebellar white mater, midbrain \& medulla oblongata (motor neurons) respectively. $1,2,3 \&$ 4 represent bifenthrin group after $1 \mathrm{w}, 2 \mathrm{w}, 3 \mathrm{w}, 4 \mathrm{w}$ respectively.

Control group: showing normal histology of cerebellum (A), cerebellar white mater (B), midbrain (cerebral cortex) (C) \& motor neurons in medulla oblongata (D). Bifenthrin group 1w showing: necrosis of some Purkinje cells (A1), mild congestion (B1), neuronophagia (C1), perineuronal edema and hemorrhage (D1). Bifenthrin $2 \mathrm{w}$ showing: necrosis of most of Purkinje cells (A2), diffuse gliosis (B2), proliferation of microglia cells around dead neurons (beginning of neuronophagia) (C2), neuronal necrosis (D2). Bifenthrin 3w showing: widespread necrosis of Purkinje cells (A3), diffuse gliosis (B3), necrotic neurons (C3), neuronal necrosis and perineural edema (D3). Bifenthrin 4w showing: loss of some Purkinje cells (A4), demyelination (B4), neuronophagia (C4), widespread neuronal necrosis with marked edema (thin arrow) and proliferation of perineural satellite oligodendroglia cells around the cell body of motor neurons 'satellitosis' (thick arrow) (D4).

\section{Discussion:-}

Bifenthrin (BF) is one of the widely used pyrethroid insecticides applied alone or in combination with other insecticides to controls a wide variety of insect pests in agriculture, horticulture and forestry (Johnson et al., 2010). In the current study, we provided evidence that bifenthrin induces toxic effects on the liver, kidney and brain associated with oxidative stress and inflammatory responses. In addition, we demonstrated that the induced tissue injury involves caspase-mediated cell death. 
In the present investigation, administration of bifenthrin to rats at a dose level equivalent to $1 / 10^{\text {th }}$ oral $\mathrm{LD}_{50}$ for 28 days induced significant increases in serum ALT, AST, LDH and ALP activities with reduction of serum total protein level.

Similar to our findings, bifenthrin induced elevation in serum ALT in mice (Nieradko-Iwanicka et al., 2015), plasma ALT, AST and ALP in goat (Khan et al., 2013) and LDH and ALP activity in rainbow trout (Velisek et al., 2009). Other pyrethroids were reported to induce similar effects in rats (Hocine et al., 2016; Rjeibi et al., 2016). Contrary to our results, Zhang et al (2015) reported that mice injected with bifenthrin for 7 days showed no change in liver marker enzymes.

Hepatocellular degeneration or necrosis causes leakage of intracellular ALT to serum due to damage of cell membranes. ALT is considered the most sensitive marker enzyme for liver function, where the rise in serum activity is correlated with the degree of liver damage. In acute hepatotoxicity, ALT activity elevates to peak within 1-2 days (Hall and Everds, 2014; Plaa et al., 2014). AST is not specific to the liver like ALT, as it is present equally in liver and heart. In liver injury, blood AST elevates with ALT where it leaks out cell membranes to peak within 24-36 hours. In cardiac affections, AST activity increases while ALT is only slightly affected (Whalan, 2015).

LDH is a marker of no-specific cellular injury, as it is present in almost all tissues. Elevated serum LDH indicates cytotoxicity and cellular damage causing cell lysis (Bagchi et al., 1995). ALP is found in liver (especially the biliary tree), kidney and intestinal mucosa, therefore, ALP is not specific for the liver. Elevated ALP may be an indicator of cholestasis, liver disease and osteoclast activity (Whalan, 2015).

As most of serum proteins are synthesized in liver, the reduction in serum total protein level may be attributed to affection of synthetic function of liver as a consequence of bifenthrin treatment (Whalan, 2015). In our study, the changes in liver marker enzymes and total protein in bifenthrin-intoxicated rats correlates well with the recorded alterations in oxidant/antioxidant parameters and the histopathological alterations in liver.

Our findings revealed that subacute intoxication of rats with bifenthrin caused significant elevations in serum BUN and creatinine levels. The nephrotoxic effects of other pyrethroids including cypermethrin and deltamethrin were previously reported (Gündüz et al., 2015; Soliman et al., 2015). BUN is produced from ammonia in liver and excreted by glomerular filtration. Creatinine is non-protein nitrogenous substance produced during muscle metabolism from muscle creatine and phosphocreatine. Because creatinine is filtered almost entirely by the glomerulus, it is considered a more specific marker than BUN for kidney damage by toxicants (Whalan, 2015).

Our results demonstrated that subacute intoxication of rats with bifenthrin was associated with oxidative stress evidenced by reduced serum TAC, elevated levels of MDA and NO with reduction in concentration of glutathione reduced in liver, kidney and brain. The activities of antioxidant enzymes SOD, CAT and GPx were downregulated in these organs.

Similar to our results, blood of rats exposed to bifenthrin orally or dermally for 30 days revealed oxidative stress in the form of elevated MDA level, reduced GSH level, and increased activities of SOD, CAT and GPx (Dar et al., 2013, 2015). Our findings partially agree with those of Nieradko-Iwanicka et al. (2015) who reported that mice treated with bifenthrin for 28 consecutive days showed reduced liver GPx activity while SOD activity increased. Concerning the kidney, our results are in agreement with those of Dar et al. (2015) who reported reduced SOD, CAT and GPx activities in kidney of rats dermally exposed to bifenthrin. Other pyrethroids were reported to induce oxidative stress (Hocine et al., 2016; Rjeibi et., 2016; Wang et al., 2016; Aouey et al., 2017; Martínez et al., 2018).

In accordance with our findings in the brain, rats treated with bifenthrin orally for 30 days showed increased lipid peroxidation and inhibited activities of SOD, CAT and GPx in brain (Syed et al., 2016). Studies performed in vivo and in vitro on rats demonstrated that bifenthrin increased lipid peroxidation and production of ROS, $\mathrm{NO}$ and $\mathrm{H}_{2} \mathrm{O}_{2}$ in brain with reduction of levels of GSH and activities of SOD, CAT and GPx (Gargouri et al., 2018a,b).

The changes in the oxidative stress biomarkers have been reported to be an indicator of the tissue's ability to cope with oxidative stress. The elevated MDA levels in liver, kidney and brain is indicative of high rate of lipid peroxidation with failure of body antioxidant system to detoxicate the ROS (Nordberg and Arnér, 2001). 
Cellular glutathione and antioxidant enzymes SOD, CAT and GPx are the first line of defense against the adverse effects of free radicals. The reduction of blood TAC and the depletion of tissue glutathione with downregulation of antioxidant enzyme activities of the redox system (SOD, CAT and GPx) reflect the inability of the antioxidant mechanisms to counteract the high levels of ROS produced by bifenthrin exposure, thus leading to oxidative stress and tissue damage (Zhang et al., 2017). The decrease in tissue SOD activity may be attributed to increased production of superoxide radical (Kale et al., 1999). Suppression of CAT and GPx activities is suggestive of increased enzyme utilization to detoxify the $\mathrm{H}_{2} \mathrm{O}_{2}$ resulting from lipid peroxidation. The reduction in activity of GPx may be due to a reduced level of GSH, which acts as a substrate for the enzyme (Raina et al. 2009).

Our findings demonstrated that bifenthrin increased the levels of NO in liver, kidney and brain and the proinflammatory mediators iNOS in liver and kidney and COX-2 in brain. These data suggest an involvement of inflammatory mechanisms in bifenthrin-induced toxicity in rats

Similar to results, Gargouri et al. (2018c) reported increases in expression of inflammatory mediators COX-2, IL-1 $\beta$, IL-6 and NF-kBp65 in brain, as well as the production of TNF- $\alpha$ and ROS in rats intoxicated with bifenthrin.

Elevated levels of the inflammatory mediators are suggested to be the earliest events in the development of many degenerative disorders (Niu et al., 2017). Under many pathological conditions, iNOS produces large amounts of NO, which is a major source of reactive nitrogen species (RNS). Particularly, peroxynitrite (ONOO-) can damage a wide range of cellular molecules including DNA, lipids, and proteins, and can also facilitate protein nitration, affecting structure and function of many target proteins (Iwakiri and Kim, 2015). The COX-2 pathway is involved in stressinduced brain damage. Overexpression of COX-2 is known to be both a marker and an effector of neural damage (de Oliveira et al., 2016).

In the current study, we have examined the apoptosis by measuring caspase- 3 activity and found increased activity in liver and brain of intoxicated rats. Our results agree with those of Zhang et al. (2015) who reported that bifenthrin induced liver injury through caspase-mediated mitochondrial-dependent cell death in mice. Other pyrethroids like lambda-cyhalothrin are reported to increase the mRNA expression of several genes important for apoptotic cell death, including Casp-3 in rats (Martínez et al., 2018). Generally, apoptosis is caused by ROS through activation of caspases, rise in mitochondrial permeability with the release of cytochrome $\mathrm{C}$, and cleavage of poly(ADP-ribose) polymerase (Shupp et al., 2010).

Our findings revealed that administration of bifenthrin to rats for 28 days produced degenerated area in liver with loss of cellular outlines and areas of coagulative necrosis infiltrated with inflammatory cells in the portal area. Kidney revealed congestion of blood vessels and glomeruli, necrotic renal tubules and hyperplasia of fibrocytes with leucocyte infiltration in between renal tubules. Brain revealed loss of some Purkinje cells, demyelination, neuronophagia, widespread neuronal necrosis with marked edema and proliferation of perineural satellite oligodendroglia cells around the cell body of motor neurons 'satellitosis'.

Our findings are in accordance with those of Nieradko-Iwanicka et al. (2015) who demonstrated that bifenthrin administered to mice for 28 days at $8 \mathrm{mg} / \mathrm{kg}$ induced lymphocyte infiltrations around hepatic blood vessels and biliary ducts. In addition, Zhang et al. (2015) reported that mice given intraperitoneal injections of $8 \mathrm{mg} / \mathrm{kg}$ bifenthrin for 7 days produced nuclear pyknosis and vacuolar degeneration in liver. In rainbow trout, bifenthrin induced degeneration of hepatocytes, especially in the periportal zones. Affected hepatocytes showed pyknotic nuclei and many small vacuoles or one large vacuole in the cytoplasm. Vacuole shape was typical of fatty degeneration of the liver (Velisek et al. 2009). Synthetic pyrethroids like cypermethrin and deltamethrin were reported to produce histopathological changes in liver, kidney and brain of intoxicated animals (Sankar et al., 2012; Saoudi et al., 2017).

The recorded histopathological alterations recorded in the liver, kidney and brain of intoxicated rats are compatible with the recorded oxidant/antioxidant imbalance and the changes in liver and kidney biomarkers.

\section{Conclusion:-}

We have demonstrated that bifenthrin exhibited hepatotoxic, nephrotoxic and neurotoxic effects. These were associated with oxidative stress and inflammatory responses in liver, kidney and brain that involved the activation of iNOS and COX-2 pathways. In addition, bifenthrin induced liver and renal injury through caspase-mediated apoptic cell death. 


\section{Acknowledgements:-}

We thank consult of central laboratory in Faculty of Veterinary Medicine, University of Sadat City, as we had bench space to work.

\section{Funding}

The authors declare that there are no sources of funding to be acknowledged.

\section{Authors' contributions}

Enas A. Tahoun has performed histopathological and immunohistochemical examination. Shimaa M. Abou-Zeid and Huda O. AbuBakr have performed the biochemical analysis. All authors have contributed to the experimental design, writing and revising this article.

\section{Competing interests}

The authors declare that they have no competing interests.

\section{Consent for publication}

All authors have reviewed the manuscript and approved its submission for publication.

\section{References:-}

1. Aebi, H. (1984): Catalase in vitro. Methods Enzymol., 105: 121-126.

2. Anadón, A., Martínez-Larrañaga, M. and Martínez, M.A. (2009): Use and abuse of pyrethrins and synthetic pyrethroids in veterinary medicine. Vet .J. Lond. Engl., 182: 7-20.

3. Aouey, B., Derbali, M., Chtourou, Bouchard, M., Khabir, A. and Fetoui, H. (2017): Pyrethroid insecticide lambda-cyhalothrin and its metabolites induce liver injury through the activation of oxidative stress and proinflammatory gene expression in rats following acute and subchronic exposure. Environ. Sci. Pollut. Res. Int., 24: 5841-5856.

4. Bagchi, D., Bagchi, M., Hassoun, E.A. and Stohs, S.J. (1995): In vitro and in vivo generation of reactive oxygen species, DNA damage and lactate dehydrogenase leakage by selected pesticides. Toxicol., 104: 129-140.

5. Bais, R. and Philcox, M. (1994): Approved recommendation on IFCC methods for the measurement of catalytic concentration of enzymes. Part 8. IFCC method for LDH. Eur. J. Clin. Chem. Clin. Biochem., 32: 639-55.

6. Bancroft, J.D. and Gamble, M. (2008): Theory and Practice of histological techniques". 6th Edition. Churchill, Livingstone, New York, London., Pp: 440-450.

7. Beutler, E., Duron, O.B.M. and Kelly, B.M. (1963): Improved method for the determination of blood glutathione, J. Lab. Clin. Med., 61: 882-888.

8. Choi, S.H., Aid, S., Caracciolo, L., Minami, S.S., Niikura, T., Matsuoka, Y., Turner, R.S., Mattson, M.P. and Bosetti, F. (2013). Cyclooxygenase-1 inhibition reduces amyloid pathology and improves memory deficits in a mouse model of Alzheimer's disease. J. Neurochem.,124: 59-68.

9. Dar, M.A., Khan, A.M., Raina, R., Verma, P.K. and Sultana, M. (2013): Effect of repeated oral administration of bifenthrin on lipid peroxidation and antioxidant parameters in Wistar rats. Bull. Environ. Contam. Toxicol., 91(1): 125-8.

10. Dar, M.A., Raina, R., Mir, A.H., Sultana, M. and Pankaj, N.K. (2015): Effect of Dermal Application of Bifenthrin on Acetylcholinesterase and Oxidative Stress Induced in Rat Blood, Lung and Kidney. Proc. Natl. Acad. Sci., India, Sect. B. Biol. Sci., 85(2): 431-435

11. de Oliveira, A.C.P, Yousif, N.M., Bhatia, H.S., Hermanek, J., Huell, M. and Fiebich, B.L. (2016). Poly(I:C) increases the expression of mPGES-1 and COX-2 in rat primary microglia. J. Neuroinflamm., 13: 11.

12. El-Aaser, A.A., Hindawy, D.S., Hammouda, F. and Mohieddin, O. (1977): A direct lead technique for histochemical demonstration of leucocyte alkaline phosphatase activity in blood smears. Acta Biol. Acad. Sci. Hung, 28(3): 291-8.

13. Fawcett, J.K. and Scott, J.E. (1960). A rapid and precise method for the determination of urea. J. Clin. Pathol., 13: 156-159.

14. Gargouri, B., Bhatia, H.S., Bouchard, M., Fiebich, B.L. and Fetoui, H. (2018a). Inflammatory and oxidative mechanisms potentiate bifenthrin-induced neurological alterations and anxiety-like behavior in adult rats. Toxicol. Lett., 294: 73-86. 
15. Gargouri, B., Yousif, N.M., Attaai, A., Bouchard, M., Chtourou, Y., Fiebich, B.L. and Fetoui, H. (2018c): Pyrethroid bifenthrin induces oxidative stress, neuroinflammation, and neuronal damage, associated with cognitive and memory impairment in murine hippocampus. Neurochem. Int., 120: 121-133.

16. Gargouri, B., Yousif, N.M., Bouchard, M., Fetoui, H. and Fiebich, B.L. (2018b): Inflammatory and cytotoxic effects of bifenthrin in primary microglia and organotypic hippocampal slice cultures. J. Neuroinflamm., 15(1): 159.

17. Gornall, A.G. Bradawill, C.J. and David, M.M. (1949): Determination of serum proteins by means of the biuret reaction. J. Biol. Chem., 177(2): 751-66.

18. Gündüz, E., Ülger, B.V., İbiloğlu, İ., Ekinci, A., Dursun, R., Zengin, Y., İçer, M., Uslukaya, Ö., Ekinci, C. and Güloğlu, C. (2015): Glutamine provides effective protection against deltamethrin-induced acute hepatotoxicity in rats but not against nephrotoxicity. Med. Sci. Monit., 21:1107-14.

19. Hall, R.L. and Everds, N.E. (2014): Principles of clinical pathology for toxicology studies. In: "Hayes' Principles and Methods of Toxicology". 6th ed. By: AW Hayes and CL Kruger. CRC Press, New York., Pp. 1305-1344.

20. Hocine, L., Merzouk, H., Merzouk, S.A., Ghorzi,, H., Youbi, M. and Narce, M. (2016): The effects of alphacypermethrin exposure on biochemical and redox parameters in pregnant rats and their newborns. Pestic. Biochem. Physiol., 134: 49-54.

21. Iwakiri, Y. and Kim, M.Y. (2015): Nitric oxide in liver diseases. Trends. Pharmacol. Sci., 36(8): 524-36.

22. Johnson, M., Luukinen, B., Gervais, J., Buhl, K. and Stone, D. (2010): Bifenthrin Technical Fact Sheet; National Pesticide Information Center, Oregon State University Extension Services. http://npic.orst.edu/factsheets/archive/biftech.html.

23. Kale, M., Rathore, N., John, S. and Bhatnagar, D. (1999): Lipid peroxidative damage on pyrethroid exposure and alterations in antioxidant status in rat erythrocyte: a possible involvement of reactive oxygen species. Toxicol. Lett., 105: 197-205.

24. Khan, A.M, Sultana, M., Raina, R., Dubey, N. and Dar, S.A. (2013): Effect of sub-acute toxicity of bifenthrin on antioxidant status and hematology after its oral exposure in goats. Proc. Natl. Acad. Sci., India, Sect. B Biol. Sci., 83(4): 545-549.

25. Koracevic, D., Koracevic, G., Djordjevic, V., Andrejevic, S. and Cosic, V. (2001): Method for the measurement of antioxidant activity in human fluids. J. Clin. Pathol., 54: 361-356.

26. Martínez, M.A., Ares, I., Rodríguez, J.L., Martínez, M., Roura-Martínez, D., Castellano, V., Lopez-Torres, B., Martínez-Larrañaga, M.R. and Anadón, A. (2018): Pyrethroid insecticide lambda-cyhalothrin induces hepatic cytochrome P450 enzymes, oxidative stress and apoptosis in rats. Sci. Total Environ., 631-632: 1371-1382.

27. Nieradko-Iwanicka, B., Borzecki, A. and Jodlowska-Jedrych, B. (2015). Effect of subacute poisoning with bifenthrin on locomotor activity, memory retention, haematological, biochemical and histopathological parameters in mice. J. Physiol. Pharmacol., 66(1): 129-37.

28. Nishikimi, M., Appaji, N. and Yagi, K. (1972): The occurrence of superoxide anion in the reaction of reduced phenazine methosulfate and molecular oxygen, Biochem. Biophys. Res. Commun., 46: 849-854.

29. Niu, H., Álvarez-Álvarez, I., Guillén-Grima, F. and Aguinaga-Ontoso, I. (2017): Prevalence and incidence of Alzheimer's disease in Europe: a meta-analysis. Neurologia, 32: 523-532.

30. Nordberg, J. and Arnér, E.S. (2001): Reactive oxygen species, antioxidants and the mammalian thioredoxin system. Free Radic. Biol. Med., 31: 1287-1317.

31. Ohkawa, H., Ohishi, W. and Yagi, K. (1979): Assay for lipid peroxides in animal tissues by thiobarbituric acid reaction, Anal. Biochem., 95: 351-358.

32. Paglia, D.E. and Valentine, W.N. (1967): Studies on the quantitative and qualitative characterization of erythrocyte glutathione peroxidase. J. Lab. Clin. Med., 70(1):158-69.

33. Plaa, G.L., Charbonneau, M. and Plante, I. (2014): Detection and evaluation of chemically induced liver injury. In: "Hayes' Principles and Methods of Toxicology". 6th ed. By: A.W. Hayes and C.L. Kruger. CRC Press, New York. Pp:1384-1445.

34. Prasanthi, K., Muralidharan, and Rajini, PS. (2005): Fenvalerate induced oxidative damage in rat tissue and its attenuation by dietary sesame oil. Food Chem. Toxicol., 43: 299-306.

35. Raina, R., Verma, P.K., Pankaj, N.K. and Kant, V. (2009): Ameliorative effects of alfa-tocopherol on cypermethrin induced oxidative stress and lipid peroxidation in Wistar rats. Int. J. Med. Med. Sci., 1:396-399.

36. Reitman, S. and Frankel, S. (1957): Colorimetric determination of serum oxalacetic and glutamic pyruvic transaminase. Amer. J. Clin. Pathol., 28: 56-63. 
37. Rjeibi, I., Ben Saad, A. and Hfaiedh, N. (2016): Oxidative damage and hepatotoxicity associated with deltamethrin in rats: The protective effects of Amaranthus spinosus seed extract. Biomed. Pharmacother., 84: 853-860.

38. Sankar P., Telang A.G. and Manimaran A. (2012): Protective effect of curcumin on cypermethrin-induced oxidative stress in Wistar rats. Exp. Toxicol. Pathol., 64(5): 487-93.

39. Saoudi, M., Badraoui, R., Bouhajja, H., Ncir, M., Rahmouni, F., Grati, M., Jamoussi, K. and Feki, A.E. (2017): Deltamethrin induced oxidative stress in kidney and brain of rats: Protective effect of Artemisia campestris essential oil. Biomed. Pharmacother., 94: 955-963.

40. Schirmeister, J., Willmann, H. and Kiefer, H. (1964): Plasma creatinine as rough indicator of renal function. Dtsch. Med. Wochenschr., 89: 1018-23.

41. Shupp, J.W., Nasabzadeh, T.J., Rosenthal, D.S., Jordan, M.H., Fidler, P. and Jeng, J.C. (2010): A review of the local pathophysiologic bases of burn wound progression. J. Burn. Care Res., 31: 849-873.

42. Soliman, M.M., Attia, H.F. and El-Ella, G.A. (2015): Genetic and histopathological alterations induced by cypermethrin in rat kidney and liver: Protection by sesame oil. Int. J. Immunopathol. Pharmacol., 28(4): 508-20.

43. Sunderland, D.M. (2010): Toxicology and Mode of Action of Pyrethroid Insecticides. In: Handbook of Pesticide Toxicology. $3^{\text {rd }}$ ed., R. Krieger, Academic Press, New York. Pp. 1665-86.

44. Syed, F., John, P.J and Soni, I. (2016): Neurodevelopmental consequences of gestational and lactational exposure to pyrethroids in rats. Environ. Toxicol., 31(12): 1761-1770.

45. Tsuji, R., Yamada, T. and Kawamura, S. (2012): Mammal Toxicology of Synthetic Pyrethroids. Top. Curr .Chem., 314: 83-112

46. Velisek, J., Svobodova, Z. and Piackova, V. (2009): Effects of acute exposure to bifenthrin on some haematological, biochemical and histopathological parameters of rainbow trout (Oncorhynchus mykiss). Vet. Med., 54(3): 131-137.

47. Wang, X., Martínez, M.A., Dai, M., Chen, D., Ares, I., Romero, A., Castellano, V., Martínez, M., Rodríguez, J.L., Martínez-Larrañaga, M.R., Anadón, A. and Yuan, Z. (2016). Permethrin-induced oxidative stress and toxicity and metabolism. A review. Environ. Res., 149: 86-104.

48. Whalan, J.E. (2015): Clinical Chemistry. In: A Toxicologist's Guide to Clinical Pathology in Animals. Springer International Publishing, Switzerland. Pp: 67-94.

49. Yang, Y., Wu, N. and Wang, C. (2018): Toxicity of the pyrethroid bifenthrin insecticide. Environ. Chem. Lett., 16: 1377-1391.

50. Zhang, Y., Lu, M, Zhou, P., Wang, C., Zhang, Q. and Zhao, M. (2015): Multilevel evaluations of potential liver injury of bifenthrin. Pestic. Biochem. Physiol., 122: 29-37.

51. Zhang, Z., Zhao, X. and Qin, X. (2017): Potential genotoxic and cytotoxicity of emamectin benzoate in human normal liver cells. Oncotarget., 8: 82185-82195. 